\title{
Ischaemic preconditioning and stem cell mobilisation
}

\author{
Qizhou Lian ${ }^{1,2}$; Hung-Fat Tse ${ }^{1,2}$ \\ ${ }^{1}$ Cardiology Division, Department of Medicine, the University of Hong Kong, Hong Kong SAR, China; ${ }^{2}$ Research Centre of Heart, Brain, Hormone, and Healthy Aging, the University \\ of Hong Kong, Hong Kong SAR, China
}

Ischaemic preconditioning (IPC) (1) refers to repeated brief episodes of ischaemia, which itself does not result in cells death, protects the myocardium from a subsequent ischaemic insult. A better understanding of the mechanism of this cardioprotective effect could potentially lead to the development of novel therapeutics that can be used in the clinical setting. Previous studies (2) have been mainly focused on the role of different signalling pathways, such as phosphatphosphatidylinositol 3-kinase (PI3-kinase), Akt, nitric oxide synthase, guanylyl cyclase, and mitochondrial $\mathrm{K}$ (ATP) channels, in mediating the cardioprotection during IPC. More recent studies $(3,4)$ have demonstrated that IPC-mediated cardioprotection is also related to stem cell mobilisation and production of cardioprotective cytokines which enhanced the recovery after ischaemia-reperfusion and chronic ischaemic injury.

In this Theme Issue of Thrombosis and Haemostasis, Gyöngyösi et al. (5) describe that IPC enhances mobilisation and recruitment of haematopoietic stem cells (HSC) and mesenchymal stem cells (MSC) in a porcine myocardial ischaemia-reperfusion model. The use of a clinically relevant chest model of infarction in large animals is

\section{Correspondence to:}

Hung Fat Tse, MD, PhD

Cardiology Division, Department of Medicine

The University of Hong Kong, Queen Mary Hospital

Hong Kong, China

Tel.: +852 2855 3598, Fax: +852 28186304 ,

E-mail: hftse@hkucc.hku.hk

\section{Financial support:}

This work was supported by grants from Seed Funding for Basic Research (\#10208618 to Q Lian) and Small Project Funding (\#10400639, to Q Lian); and HKU Strategic Research Theme on Healthy Ageing (to Q Lian and HF Tse) from the University of Hong Kong.

Received: December 15, 2009

Accepted: December 15, 2009

Prepublished online: April 13, 2010

doi:10.1160/TH09-12-0839

Thromb Haemost 2010; 104: 194-195 a strength of this study. During the early phase of IPC, both HSC and MSC were quickly recruited from the circulating pool to the infarction areas and border zones, suggesting that IPC might enhance stem cell mobilisation and retention into the ischaemic areas as exogenous administration of cytokines (6). Nevertheless, the functional status as well as the fate of recruited stem cells must be addressed before the IPC can be fully evaluated in the clinical setting. It has been reported that the recruited c-kit+/lin- progenitor cells accumulated in heart tissues were dysfunctional and undergoing senescence in response to ischaemia (7). Furthermore, the depletion and impairment of endogenous stem cells in patients with cardiovascular disease might also limit the mobilisation of stem cells during IPC (8).

Prior studies (9-11) have demonstrated that the paracrine effects of bone marrowderived stem cells may play a more important role than stem cell trans-differentiation in enhancing the neovascularisation of the ischaemic myocardium. Indeed, Gyöngyösi et al. showed that brief episodes of ischaemia raised the cytokines levels, including stromal-derived factor $1 \alpha$ (SDF-1 $\alpha)$ and vascular endothelial growth factor (VEGF) during the early phase of
IPC, which might contribute to the MSC and HSC mobilisation and enhancement of neovascularisation. In contrast to the measurement of the circulating levels of cytokines, it would be even more valuable to determine if local concentrations of VEGF or SDF- $1 \alpha$ were also increased in response to IPC. Furthermore, whether the recruited MSC and HSC are functional and could further contribute to the cardioprotective effects of IPC remains unclear.

In addition to providing further insight into the mechanisms of cardioprotection by IPC, this study by Gyöngyösi et al. (5) may have potential clinical implication for stem cell therapy in cardiac repair. Although different types of stem cells have been investigated as novel therapy for cardiac repair and showed initial promising results $(12,13)$, one of the major challenges that remains is the poor cell retention and survival in a hostile ischaemic environment. In rodent experiments, treatment of IPC not only promoted the survival of the transplanted skeletal myoblast via the release of paracrine factors (14), but also enhanced kit+/Lin- stem cell survival and homing to ischemic myocardium by activation of SDF-1 $\alpha /$ CXCR4 axis (15).

Taken together, IPC treatment not only protects myocardium from subsequent is-

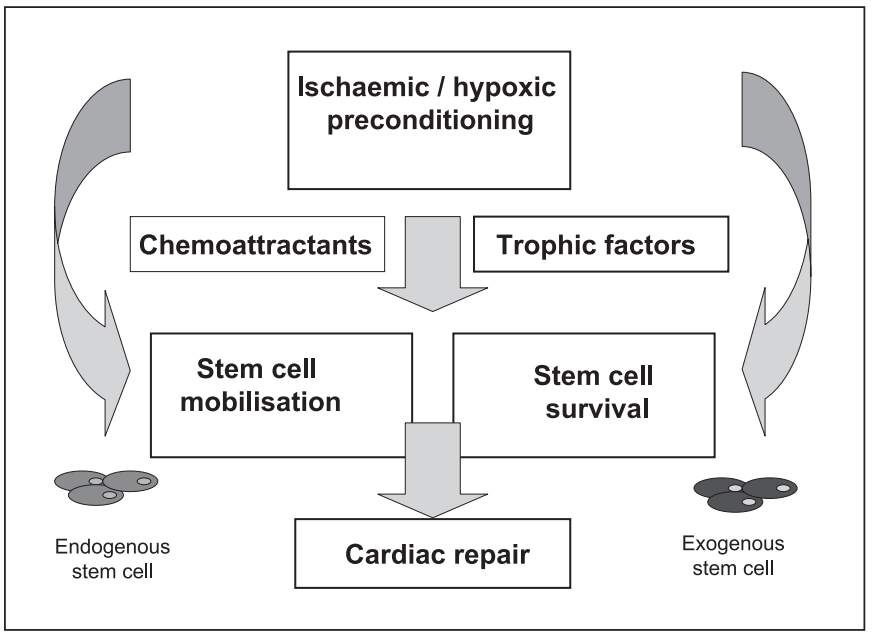

Figure 1: Potential effects of ischaemic preconditioning to enhance stem cell therapy for cardiac repair. 
chaemic insult, but also promotes endogenous stem cell mobilisation. Therefore, IPC treatment may provide a novel strategy to enhance the therapeutic efficacy of stem cell therapy for cardiac repair by mobilisation of endogenous stem cells, and improving the retention and survival exogenous transplanted stem cells (Fig. 1). The future holds much promise.

\section{References}

1. Murry CE, Jennings RB, Reimer KA. Preconditioning with ischemia - a delay of lethal cell injury in ischemic myocardium. Circulation 1986; 74 : 1124-1136.

2. Downey JM, Davis AM, Cohen MV. Signaling pathways in ischemic preconditioning. Heart Fail Rev 2007; 12: 181-188

3. Ii M, Nishimura H, Iwakura A, et al. Endothelial progenitor cells are rapidly recruited to myocardium and mediate protective effect of ischemic preconditioning via "imported" nitric oxide synthase activity. Circulation 2005; 111: 1114-1120.
4. Kamota T, Li TS, Morikage N, et al. Ischemic preconditioning enhances the mobilization and recruitment of bone marrow stem cells to protect against ischemia/reperfusion injury in the late phase. J Am Coll Cardiol 2009; 53: 1814-1822.

5. Gyongyosi M, Posa A, Pavo N, et al. Differential effect of ischaemic preconditioning on mobilisation and recruitment of hematopoietic and mesenchymal stem cells in porcine myocardial ischaemicreperfusion. Thromb Haemost 2010; 103: 376-384.

6. Huang PP, Yang XF, Li SZ, Wen JC, Zhang Y, Han ZC. Randomised comparison of G-CSF-mobilized peripheral blood mononuclear cells versus bone marrow-mononuclear cells for the treatment of patients with lower limb arteriosclerosis obliterans. Thromb Haemost 2007; 98: 1335-1342.

7. Torella D, Ellison GM, Mendez-Ferrer S, et al. Resident human cardiac stem cells: role in cardiac cellular homeostasis and potential for myocardial regeneration. Nat Clin Pract Cardiovasc Med 2006; 3 (Suppl 1): S8-13.

8. Egan CG, Caporali F, Huqi AF, et al. Reduced levels of putative endothelial progenitor and CXCR4+ cells in coronary artery disease: kinetics following percutaneous coronary intervention and association with clinical characteristics. Thromb Haemost 2009; 101: 1138-1146.

9. Timmers L, Lim SK, Arslan F, et al. Reduction of myocardial infarct size by human mesenchymal stem cell conditioned medium. Stem Cell Res 2007; 1: 129-137.

10. Gnecchi M, He H, Liang OD, et al. Paracrine action accounts for marked protection of ischemic heart by Akt-modified mesenchymal stem cells. Nat Med 2005; 11: 367-368.

11. Tse HF, Zhu SG, Zhang OY, et al. Paracrine effects of direct intramyocardial implantation of bone marrow mononuclear cells to enhance neovascularization in chronic ischernic myocardium. Eur J Heart Fail 2007; 9: 747-753.

12. Menasche P. Stem cells for clinical use in cardiovascular medicine. Thromb Haemost 2005; 94: 697-701.

13. Tse HF, Thambar S, Kwong YL, et al. Prospective randomized trial of direct endomyocardial implantation of bone marrow cells for treatment of severe coronary artery diseases (PROTECT-CAD trial). Eur Heart J 2007; 28: 2998-3005.

14. Niagara MI, Haider HK, Jiang SJ, et al. Pharmacologically preconditioned skeletal myoblasts are resistant to oxidative stress and promote angiomyogenesis via release of paracrine factors in the infarcted heart. Circ Res 2007; 100: 545-555.

15. Tang YL, Zhu W, Cheng M, et al. Hypoxic preconditioning enhances the benefit of cardiac progenitor cell therapy for treatment of myocardial infarction by inducing CXCR4 expression. Circ Res 2009; 104: 1209-1216. 